\title{
Sociocultural dynamics and information civilization as one of the vectors of the evolution of 21 st century culture
}

\author{
Rida Zekrist $^{1, *}$, Maxim Bakhtin ${ }^{2}$ \\ ${ }^{1}$ Kostanay Social and Technical University, St. Kobylandy Batyr, 27, 110010, Kostanay, Kazakhstan \\ ${ }^{2}$ Publishing house "Encyclopedist-Maximum»
}

\begin{abstract}
The article considers the problem of developing conceptual principles of philosophical and cultural studies of society that are adequate to its current metastable state, taking into account its transition to the era of a new type of cultural development (information, project management culture, etc.). The global informatization of society, the conditions under which the cultural information environment functions, is in our time the main source of social inequality. The relevance of the study is due to the transition to a new type of cultural development in the form of selfstructuring of the personality, directly related to the self-structuring of the noosphere on the way of a wide awareness of the fact of knowledge, streamlining their structure, as well as determining mutual transitions between knowledge and information and obtaining knowledge from information. The specificity of the development of information culture is shown, which contributes to the reduction of uncertainty in the functioning of various social or innovative clusters with the help of management signals. It is also shown that it becomes a condition for society to gain additional degrees of freedom. New approaches used in the work are developed on the basis of a synergistic expansion of the research method. The methodological basis of the study adopted the ideas and methods of modern systemology, philosophical synergetics and structural epistemology. The analysis shows that the mass culture of the mid-twentieth - beginning of the twenty-first centuries. remains a relatively unimaginable phenomenon in terms of general and philosophical cultural studies.
\end{abstract}

\section{Introduction}

For each new generation of people, a supersaturated world for perception looks more and more complex, confused and uncontrollable. In our opinion, the works of philosophers, culturologists, and sociologists, as a rule, illuminate the problem from the standpoint of sociohumanitarian knowledge. However, global informatization of society, the development of computer networks leads to the formation of interdisciplinary approaches. At a new stage of development, a number of scientists consider the problem from synergetic, natural-scientific

\footnotetext{
*Corresponding author: Zekrist@mail.ru
} 
positions, for example, S. P. Kapitsa, I. S. Prigogine, I. Stengers, M. S. Kagan, E. V. Lanko, G. G. Malinetskiy $[1,2,3,4]$.

In connection with the above two ways to solve the problem, we note modern research that outlined the horizon of the key research objectives.

The key concepts for us are those studied by L. Quintanilla-Sierra, C. García-Arévalo, J. C. Rodriguez-Cabello [5] using biomodeling as an example, self-organizing structures, the concept of self-assembly and their consequences in (biological) systems. An analogy with social systems is appropriate here. A synergistic approach to the analysis of both natural and social phenomena and patterns of development is legitimate provided that the methodological and conceptual concepts and principles of synergy are correctly and fully taken into account and correlated with the specific features of the object of study.

Since the theory of self-organization of complex systems was formed in the bosom of biology, we also turn to the article "The Idea of Will" by Dorenbosch Drs. M.M. [6], in which attention is aimed at studying the problem of conscious will from the point of view of the needs of the neuromuscular system, and not from the anthropocentric point of view. In analyzing the subject area, in our opinion, the researcher should pay attention to the relevance of using the system-synergetic method for a deeper understanding of the connection of the will with our everyday behavior than with the will itself. With this formulation of the question, it becomes important to describe what biological self-organization is, spontaneous patterning, autopoietic behavior of systems (biological).

Computer simulation methods allow the researcher to create artificial social worlds, to study real social processes with their help, significantly expanding their cognitive capabilities. It is clear that computers using software systems of artificial intelligence can recognize information, make decisions, and, therefore, can be considered as cognitive systems. But for social theory, the main problem is that as a result of the interaction of human and artificial intellects, a qualitatively new, virtual reality is born, and changes are global in nature.

Global informatization of society, the development of computer networks leads to the fact that many types of business, services, leisure activities are increasingly moving into virtual space. Not only new forms of communication appear, but also new artificial objects with which people can communicate and establish strong social ties.

Colonization of virtual space poses a challenge for scientists to analyze virtual systems social communities consisting of people and computer devices with artificial intelligence. The most relevant social problems of virtualization of social relations include:

- determination of norms, rules of behavior in the virtual world;

- analysis of the impact of virtual social processes on the ordinary, everyday life of the individual.

Thus, the above review of articles showed that the establishment of scientifically based norms and rules for the functioning of virtual systems will significantly reduce the risk of negative unforeseen consequences of cardinal changes witnessed by modern humanity.

The modern information culture also acquires significant social significance because today it (like science a few years ago) has become a direct productive force.

\section{Materials and methods}

New approaches used in the work are developed on the basis of a synergistic expansion of the research method. The methodological basis of the study adopted the ideas and methods of modern systemology, philosophical synergetics and structural epistemology. The novelty of the provisions, conclusions and results of the study follows from the undertaken analysis of the processes of self-organization in the evolution of culture in the context of a synergistic 
extension of the method of philosophical cultural studies, taking into account the whole system of basic concepts of synergetics and their subtle relationship.

\section{Relevance}

In this regard, it is the synergetic extension of the method of cultural studies that becomes most relevant. The whole cultural thesaurus is subject to deeper and more detailed reading from the standpoint of synergetics: invariant direction signs and communicative symbols, depending on the context, reminder images and expressive stimuli-regulators of the semantic, emotional-motivational, spiritual sphere, material and practical actions and relationships and finally, the creative context of human evolution and culture. On the other hand, the same thesaurus forms hierarchical social structures, individual psychological, group and social goals, means and methods of achieving them.

Since culture is currently shifting to the epicenter of human activity, the spectrum of vectors of its possible further development and evolution is of great importance. From the above extract, it is easy to see that the epicenter of culture is shifting from the object-subject and emotional-creative sphere to the sphere of design and management and information culture, which in turn can be divided into informational, business (business culture), virtual and visual.

The development of modern information culture today becomes a necessary condition for the adequate socialization of the individual and increase the social status of each person. Only the entry of a subject into a locally and globally distributed information environment (info environment) of one or another developed system of professional or social activity ensures the synchronization of psychological and social time of life.

The explosive development of modern technology made it possible to thousandfold increase both the volume and speed of transmission of information flows in society. However, the growth of the information avalanche occurred for the most part spontaneously, uncontrollably, which led to many negative consequences, some of which were noted in the previous subsection. Information as a leading part of the culture of the future (like culture as a whole, and society itself) therefore needs a controlling influence from the latter. But the management phenomenon for its successful application also requires deep scientific and philosophical reflection.

\section{Discussion}

Researchers, in particular, P. Sorokin, V. Bibler did not indicate what specific psychological and social phenomena and factors would be associated with the choice of a new vector of cultural evolution, although many emphasized the importance of a creatively creative beginning. P. Sorokin limited himself to the general statement: "We live and act in one of the turning points of human history ..." [7]. V. Bibler formulates a promising personal and universal mission of culture: "Thus, a new universal society is growing - a culture society a special, somewhat close to polis sociality, more precisely, a form of free communication of people in the power field of culture, dialogue of cultures" [8].

In recent years, the qualitative composition of the information circulating in developed countries has radically changed. In it, unified declarative and procedural political, bureaucratic, and technocratic components occupy an increasing place. By virtue of this, the mental and spiritual potential of each individual is in a blurred and isolated state. At the same time, the personality itself is increasingly oriented towards disparate attractive, fashionable and prestigious roles. According to the famous philosopher Karl Jaspers, "an increasing number lead an existence divorced from the whole ... the world falls into the power of 
mediocrity, people without destiny, without differences and without a genuine human being" [9].

That is why those who would like to humanistically feel, think productively and act effectively, not only on their own, but also as an organic part of the people, their country and universal culture, should look more closely at the essential connections and unity of the material and spiritual world. For this, it is necessary to seek and develop new meanings and solutions, reasonably and tolerantly measure personal ambitions and cooperation with others, strive for a balance of desired and prestigious possessions and deep spiritual empathy. To achieve this, it is necessary to form an integrative understanding of the world and attitude, and, therefore, holistic, adequate and effective knowledge.

Napoleon's "Man completely", Marx's public man, Bibler's self-designing personality under the conditions of the "force field of culture" is being transformed (at present and will be transformed in the future) in the sense that, in creating himself, a person must also create a new culture, free from the pressure of the "instincts of excessive fertility" ... Therefore, culture without a new "cultural man" is impossible, just as a new man is impossible without a new culture.

There is already reason to conclude, we repeat, having a general cultural meaning. Homo sapiens (Homo sapiens, thinking) - this is not a relevant (not essential) definition of a person. The context of the human brain is by no means always a context of cultural (supernatural) creativity and co-creation. And culture itself was the result of the creative mechanism of individuals and societies.

For each new generation of people, a supersaturated world for perception looks more and more complex, confused and uncontrollable. Excessive absorption of the flow of disparate information coming through training channels, the media, the Internet, e-mail and other means of communication negatively affects the stability of attitude, the certainty of cultural and human relations and expectations. The efficiency of business and the state also suffers, since an information avalanche sharply limits the time for deliberate reflection and substantiation of strategic decisions. And yet, despite the negativity of the modern information avalanche noted here, it should be concluded that the "non-demographic" culture of the future will be an information culture.

"Systematic studies of the historical process of the emergence and increasingly complex ordering of relationships in interactions reveal the meaning of the concepts of goal, information and control in the dialectics of the objective world, contributing to the disclosure of the very mechanism of self-organization of matter. It is the formation of functional systems of self-regulation processes (in the evolution of culture) and the formation of the modern image of human activity that marked the ascent of matter to the following levels of development"'[10].

The modern information culture also acquires significant social significance because today it (like science a few years ago) has become a direct productive force. So, software and information tools and information technology for project management, electronic methods of doing business in large companies make us abandon the idea of information production as the production of only services or consumer goods. From now on, information production has become an invariant of social production as a whole.

The creation and functioning of the information environment of large corporations is becoming an integral part of material production. The modern information environment provides both the necessary level of management and improvement of labor, the growth of its productivity and quality, and the adequate updating of the structure of production relations. These relationships become informational mediated. To a large extent, they can now be carried out through the information environment.

The information type of production relations occupies an increasingly significant place in various production spheres. In this case, the information environment becomes the most 
important factor in the socialization of the individual, social solidarity, creative selfrealization of the individual and, finally, overcoming the economic and political alienation from culture itself. The alienation investigated by Marx sheds light on the position of individuals in society and therefore makes it possible to understand the mechanisms of lies and ignorance. "Social power, that is, the multiplied productive force arising due to the division of labor by the joint activities of various individuals ... seems to these individuals not as their own combined power, but as some kind of alien, outside their standing power, the origin and development trends of which they are nothing they don't know "[11].

Here, indeed, there is something to think about, since the manipulation of human motives and thoughts contradicts the desired aspirations for democracy at their very foundation, depriving the meaning of the concept of freedom of thought, the fullness (meaningful) of life, and the joy of intellectual communication.

To date, information monsters such as CNN, FOX, NBC, CBS, etc. have embraced the global information market or radically influence it. In turn, they themselves express the interests of only six owners - the largest US media corporations, including giants Viacom, AOL-Time-Warner, Disney, General Electric, Ruppert Murdock's News Corporation and Bertelsmann.

Studies show that an ordinary resident of the United States with a $90 \%$ probability receives information controlled by these six masters of public consciousness, who, moreover, as practice shows, are not inclined to contradict each other (hidden monopoly). Thus, the role that alternative initiatives and the points of view of civil society should play in a democratic country pass into the egoistic voluntaristic order of the media that block and manipulate free consciousness.

A hundred years ago, the outstanding neuropsychologist V. M. Bekhterev in the book "Suggestion and its role in public life" (1903) [12] substantiated the connection of suggestion with the manipulation of consciousness. His conclusions boiled down to the following: the fundamental difference between suggestion and the belief that suggestion is an invasion of the consciousness of external ideas without the direct involvement of the personal "I" in this act, without presenting full logical conclusions, but with a limitation or distortion of the facts used.

Along with the general coordinated opposition to the manipulation of consciousness and fooling on the part of civil society, the internal potential of one's own intellect can be mobilized. This is both possible and necessary to do, because at its core, intelligence is most clearly expressed in the ability to avoid stereotyped thoughts, discover patterns, anticipate the unknown, and invent new things.

Even at the dawn of the emergence of informatics as a science, Yu. A. Schreider [13] expressed the idea that turning knowledge into information can make them a meaningless written or electronic dump of data, if you do not make regular efforts within the framework of the general culture to update the information itself and to creating tools for convenient access to the information environment to recreate the necessary knowledge.

The information environment is not only a means of storing knowledge in a transformed, socialized form, it is also a way of self-structuring knowledge and fixing hyperlinks to it. Under the new informational conditions, the specific meaning of culture as an intermediary is manifested in the elimination of the ontological gulf between knowledge and information, between intellectual intuition, reflection and personal creativity, on the one hand, and automated information networks, on the other. Today, between the knowledge "in man" and their representation in written or electronic media, a cultural-evolutionary gap has formed, which requires constant bridge building between the information-knowledge, creative activity of the subject perceiving or interpreting new knowledge and the alienated socialized one (and quite often - on the contrary, an antisocial) source of fixed information. 
A significant increase in the importance of information culture in our time has several reasons. They are associated, firstly, with a significant reduction in the standard terms for the implementation of organizational and project activities; secondly, with an explosive increase in the volume of recorded information and, as a result, with a deterioration in the structure of knowledge representation, both professional and humanitarian (universal); thirdly, with the fact that the acceleration of the processes of economic and technological development makes a significant part of people who perform highly professional work retrain several times throughout their lives. The absence of such an opportunity leads them out of the productive or significant social spheres of activity.

It is the information and knowledge threshold that in our time is the main source of social inequality, becoming the cause of a new social conflict. "Modern models of management and self-organization help to build an interdisciplinary evolutionary concept, free from teleological assumptions. Universal evolution is seen as a sequence of "posterior" effects of competition and selection mediated by specific crises.

We are talking about crises of a special type, which are caused not by spontaneous changes in the environment, but by the own activity of nonequilibrium systems, natural or social, and its consequences. As a special analysis showed, it is adaptation not to external factors, but to ITS (internal) increased opportunities that stimulates qualitative leaps in development, since they become an alternative to self-destruction.

The development of world-wide means of communication (telephone, telegraph, "Internet" and other computer networks), as well as the media, including electronic ones, poses new problems for both biological and social nature. "The availability of cheap computers and communications will change the relationship between countries and socioeconomic groups within states. Society will again stir up from issues related to the equality of all its members. After all, the information highway should serve all citizens, and not just the technical and economic elite "(Bill Gates." The Road to the Future"). These words of one of the founders of the computer revolution should be heeded, if only because now, in the conditions of the rapid development of information technologies, the prospects of the state and the individual will depend on the degree of involvement in this process. An informationally uncultured person who does not permanently reside in a socially organized information environment automatically becomes a civilizational marginal.

It follows that the assumption of V.S. Bibler about the transition to a new type of cultural development in the form of self-structuring of a person in our era is directly related to selfstructuring of the noosphere on the way of a wide awareness of the fact of knowledge [7], streamlining their structure, as well as determining mutual transitions between knowledge and information and obtaining knowledge from information (i.e., assimilation of knowledge).

On the one hand, information is materialized, alienated from the process of its generation and socialized form of knowledge, on the other hand, information is a simplified, model representation of knowledge, which also includes prototypes of knowledge, skills and procedures of reproduction and creative development of samples. In modern culture, the principle is the impossibility of the functioning of the information environment as a space of social information outside the knowledge and skills inherent in specific highly qualified people and transmitted directly through them.

In general, the conditions under which the cultural information environment functions can be divided into "ontogenetic" and "phylogenetic". The first of them are generated by the efforts to adapt their own activities to the conditions of the information environment, leading to its local changes. The second is the efforts that cause the general evolution of the cultural information environment itself.

It is appropriate to note here that the deep cultural gap between state governing bodies and structures of social self-organization is due precisely to the neglect of the connection and differences between information and knowledge. The state, as a rule, deals with alienated and 
coarsened information, while society deals with direct knowledge and its creative reconstruction.

If the ratio "management information - statistical signal" is specific for government agencies, then the relationship "social information - specific public knowledge" has significant completeness. If in the first case, information culture helps to reduce the uncertainty in the functioning of various social or innovative clusters with the help of management signals, then in the second case, information culture (i.e., various social information as a form of existence of public knowledge) becomes a condition for society to gain additional degrees of freedom .

The criteria for assessing the level of information culture are also different in these two cases. In the first case, the measure of culture (information content) is determined situationally: the degree of removal of uncertainty in this particular situation. In the second case, the information content of knowledge is assessed by its necessary participation in solving specific problems. So, today massively replicated truism turns out to be more culturally informative than the complex algorithm of a separate - peripheral for this culture control operation.

R. F. Abdeev points out that in the minds of most people the concept of "management" is usually associated with submission "... how to explain the paradox that in dozens of books on economics a great many schemes without feedback are called" control schemes ", whereas in reality they reflect only the hierarchy of vertical subordination of the lower links to the higher links of the command and administrative system that carried out the "impact" and led to today's collapse "[14]. However, as you know, the concept of "hierarchy" is associated with the concept of "non-hierarchy." Defining the concept of leadership on the basis of a nonhierarchical structure, V. V. Druzhinin and D. S. Kontorov called non-hierarchical structures without leaders "equilibrium".

This paradox is easy to remove, given the evolutionary path traveled by culture. "The control mechanism was not invented by people, but was formed in the process of evolution of wildlife. A man learns it and uses it for his own purposes ... He constantly acquires something as a result of previous events, trials, mistakes and successes, their evaluation and selection. Therefore, it changes in one or the other, and is constantly evolving socially. This forms the thesaurus, nourishes the intuition of a person and gives him the opportunity to navigate in a difficult environment, make the necessary decisions and in unforeseen situations, which is not yet available to machines, "artificial intelligence" [14].

R. F. Abdeev, using his own developed concept of a two-loop control system, reveals the informational essence of this phenomenon: "From a worldview perspective, it is interesting to note that the cyclical nature of control processes overlaps with quantum concepts in physics. Indeed, each information-management cycle in the first circuit is a quantum of regulation, i.e., an elementary complete act of regulation. The totality of such acts ensures the stability of the object.

And each cycle in the second circuit (the formulation of grains of information, the experience of a new theoretical concept and the use of the latter when making the next decision), as an elementary act of introducing a new one, is a quantum of development. The process of self-development is made up of such quanta.

The concept of a two-loop structure of the control mechanism is based on the analysis and generalization of the works of many natural scientists. In particular, I. I. Shmalgauzen distinguished between the stabilizing form and the moving form of "natural selection leading to progressive changes" [14].

The "father" of cybernetics N. Wiener pointed to the informational and evolutionary meaning of the control phenomenon. "Sustainability and learning are two forms of communicative behavior ... Living organisms, in particular higher species of living 
organisms, are able to change their behavior based on past experience," wrote Wiener, referring to the achievement of specific anti-entropic goals [15].

The most massive and active consumer of management science is management. The management task is complicated many times over when moving from individual firms and corporations to multinational companies and managing the entire global economy (if at all possible). Culture as a phenomenon of human existence inevitably requires communication, corporatism, community, collectivism for its existence, from which it is easy to conclude that the main line of human development is its unification.

\section{Conclusion}

Despite the fact that the mass culture of the mid-twentieth - the beginning of the twentieth! centuries became for most people a part of the everyday social world, it remains a relatively little meaningful phenomenon from the point of view of general and philosophical cultural studies. New approaches here can be developed on the basis of a synergistic extension of the research method.

Indeed, a trinitarian system-synergetic analysis allows us to re-structure the well-known social functions of mass culture:

a) general socialization (inculturation) of the individual as a process of mass mastery of modern everyday, everyday culture, the formation of a modern way of life;

b) functional specialization in the field of mass professions and types of labor employment;

c) mass distribution of unique cultural meanings of science and art, engineering and technology from the level of higher forms of specialized culture of civil society and the state to the level of everyday consciousness.

The main problems of mass culture are related to the function of adequate and timely translation of the increasingly intensive flows of information and knowledge from highly specialized areas of various forms of social consciousness and social practice into mass consciousness. Moreover, the processes of information transfer are now being carried out in parallel both on a national and transnational scale, both for the needs of the project-targeted and non-project cyclical activities - in order to increase the consumption and reproduction of information and knowledge, expand the types of goods, services and the functioning conditions of most people. The second side of this "popularizing" function and related problems is the removal of instinctive tensions and the necessary relaxation of subconscious complexes.

From the synergetic point of view, the problem here is the contradiction between converging regimes of attraction to various cultural invariants and diverging regimes with aggravation associated with inadequate mass infantilization and primitivization of cultural achievements. In other words: between the distribution of cataloged libraries of reliable knowledge and encyclopedic dictionaries, galleries and art albums, informative Internet sites, etc., on the one hand, and the industry of mass entertainment and entertainment, gambling virtual games, symbolic systems of extremism and sectarianism - with other. Spiritually destructive trends in popular culture, from this point of view, can be removed by introducing restrictions on the resources of the regime with exacerbation and the transition to coherent forms of interaction between subjects and objects of culture.

According to the law of unity and struggle of opposites, the development of a regime with aggravation due to the energy of mass communication and the accompanying diversification of the manifestations and functions of mass culture are combined with an increase in the level. On this basis, new marginal forms of organizing the "cultural competence" of the modern person of the crowd, their socialization and inculturation are being rapidly approved. 
The place of immanent processes of cultural self-organization is occupied by a new system of control and manipulation of the human consciousness and subconscious, interests and needs, value orientations and behavioral attitudes. Thus, cultural-generating forms of activity are limited and forced out onto the periphery of society. Such is the payment of humanity for the incoherence of objective processes of social modernization, for the lack of synergism in the evolution of culture.

In these circumstances, the effectiveness and substantive relevance of the household family and everyday civic cultures is lost. This is especially true for transitional communities.

Thus, ordinary mass culture is on the verge of a new bifurcation. Moreover, the optimal choice is possible in the direction of combining (synergy) of two development vectors:

- innovative-industrial cultural-national type of vector prevailing at the turn of the XX-XX! cc.;

- information and post-industrial, in many ways already transnational development vector.

Future research prospects will address issues of penetration into the sociological aspect of the synergetics of culture, in connection with which, the basic concepts of classics are updated. Future research will be oriented toward participating in these studies, which requires innovative ideas and solutions that can create discussions.

\section{References}

1. I. Prigozhin, I. Stengers, Order out of chaos (URSS, M., 2014) http://yanko.lib.ru/books/betweenall/prigogine-stengers_ru.htm

2. S.P. Kapitsa, S.P. Kurdyumov, G.G. Malinetskiy, Synergetics and forecasts for the future (M., 2007) spkurdyumov.ru > sinergetika-i-prognozy-budushheg

3. G.G. Malinetskiy, The future of Russia is in the mirror of synergetics (Book House "LIBROCOM", M., 2009) http://spkurdyumov.ru/misc/budushhee-i-nastoyashheerossii-v-zerkale-sinergetiki/

4. G.G. Malinetskii, A.B. Potapov, Modern problems of nonlinear dynamics. Global Trends (2015) http://www.cia.gov/cia/publications/globaltrends2015

5. L. Quintanilla-Sierra, C. García-Arévalo, J. C. Rodriguez-Cabello, Materials Today Bio 2 (2019) DOI: 10.1016/j.mtbio.2019.100007

6. Drs.M.M. Dorenbosch, The Idea of Will (2015) http://cogprints.org/9841/index.html

7. P.A. Sorokin, Man. Civilization. Society (M., https://sociology.knu.ua/sites/default/files/library/elclosed/sorokin.pdf.

8. V.S. Bibler, Culture. Collection 50/50. Dictionary experience of new thinking (M., 1989) https://studfile.net/preview/2689976/

9. K. Jaspers, The meaning and purpose of history (M., 1991) https://imwerden.de/pdf/jaspers_smysl_i_naznachenie_istorii_1991.pdf

10. R.F. Abdeev, Philosophy of information civilization (M., http://filosof.historic.ru/books/item/f00/s00/z0000892/st000.shtml

11. K. Marx, F. Engels, Op. 2nd ed. 3 https://www.marxists.org/russkij/marx/cw/

12. V.M. Bekhterev, Suggestion and his role in public life (Edition of K.L. Ricker, St. Petersburg, 1908) http://opentextnn.ru/old/man/index.html@id=1545

13. Yu.A. Schreider, Equality, similarity, order (Nauka, M., 1971) https://math.ru/lib/book/djvu/shodstvo.djvu 
14. E.M. Khakimov, Dialectics of hierarchy and non-hierarchy in philosophy and in scientific knowledge (Feng., Kazan, 2007) http://cheloveknauka.com/dialektika-ierarhiii-neierarhii-v-filosofii-i-estestvoznanii

15. N. Wiener, Cybernetics and society (M., 1958) https://www.gumer.info/bibliotek_Buks/Science/viner/intro.php. 